\title{
Composition and biological assays of the leaf essential oil of Asparagus flagellaris (Kunth) Bak
}

\author{
Oluwakayode O. Odeja', Michael Gabriel Ibok ${ }^{2^{*}}$ (D) and Ejike O. Okpala ${ }^{3}$
}

\begin{abstract}
Background: Asparagus flagellaris leaves are ethnomedicinally used to treat syphilis, gonorrhea and other sexually transmitted diseases (STDs), with no reports on the volatile constituents. This study was aimed to quantitatively and qualitatively characterise the composition of essential oil, evaluates the free radical scavenging and antimicrobial capacity of the essential oil.

Methods: The essential oil was isolated by hydrodistillation method using all-glass Clevenger-type apparatus, while the identification and quantification of constituents were performed by gas chromatography-mass spectrometry (GC-MS) technique. The antioxidant activity on 2, 2-diphenyl-1-picrylhydrazyl (DPPH) was evaluated and the oil was also tested against 10 strains of microorganisms consisting of 6 bacteria: Escherichia coli, Salmonella typhi, Klebsiella pneumonia, Pseudomonas aeruginosa, Staphylococcus aureus and Bacillus subtilis and 4 fungi: Candida albicans, Penicillium notatum, Aspergillus niger and Rhizopus spp. using broth dilution and surface plate methods, respectively.

Results: A pale yellow essential oil with a characteristic scent was obtained, with a yield of $0.80 \%(\mathrm{w} / \mathrm{w})$. A total of 28 compounds accounting for $97.41 \%$ of the total oil contents were identified. The oil was predominated by Thymol and its derivatives, accounting for $57.48 \%$. The most abundance (\% area) constituents of the essential oil were 5-Thymyl tiglate (18.49\%), Thymyl-2-methyl butyrate (17.34\%), Thymol hydroquinone dimethyl ether (10.52\%), Thymol methyl ether (9.42\%) and 5-Propyl-1, 3-benzodioxole (4.59\%). The essential oil showed a significant free radical scavenging activity compared to the standard antioxidant drugs used in this study, with \% inhibition varying from $88.06 \pm 0.0001$ to $93.05 \pm 0.0006$. The leaf essential oil exhibited antimicrobial activity on all the tested organisms at 500-125 $\mu \mathrm{g} / \mathrm{mL}$, with an 18-10 mm inhibitory zone.
\end{abstract}

Conclusion: The leaf essential oil of $A$. flagellaris contains notable chemical compounds responsible for its antioxidant and antimicrobial activities.

Keywords: Antioxidant, Antimicrobial, Asparagus flagellaris, Chemical constituents, Thymol derivatives

\section{Introduction}

Medicinal and aromatic plants have been used for decades and are still relevant today as alternative therapies. Herbs are used all over the world, especially in developing countries. Historically, herbs represent the route sources of most drugs [1].

\footnotetext{
* Correspondence: michaelibok@ymail.com

${ }^{2}$ Department of Chemistry, University of Ibadan, Ibadan, Oyo State, Nigeria

Full list of author information is available at the end of the article
}

Asparagus flagellaris (Kunth) Bak. is widespread in Northern and Southern Nigeria [2]. It belongs to the family Asparagaceae. It grows to a height of about $1 \mathrm{~m}$ and is the scandent, more or less erect plant with arching spiny branchlet as shown in Fig. 1 [3].

It has a variety of medicinal uses across the continent of Africa. The branchlets (cladodes) are the main ingredient to combat guinea worm and ointment for hair growth [2]. The stem and leaves are used for treating syphilis, gonorrhea and other sexually transmitted diseases (STDs) [2],

\section{Springer Open}

(อ) The Author(s). 2021 Open Access This article is licensed under a Creative Commons Attribution 4.0 International License, which permits use, sharing, adaptation, distribution and reproduction in any medium or format, as long as you give appropriate credit to the original author(s) and the source, provide a link to the Creative Commons licence, and indicate if changes were made. The images or other third party material in this article are included in the article's Creative Commons licence, unless indicated otherwise in a credit line to the material. If material is not included in the article's Creative Commons licence and your intended use is not permitted by statutory regulation or exceeds the permitted use, you will need to obtain permission directly from the copyright holder. To view a copy of this licence, visit http://creativecommons.org/licenses/by/4.0/. 


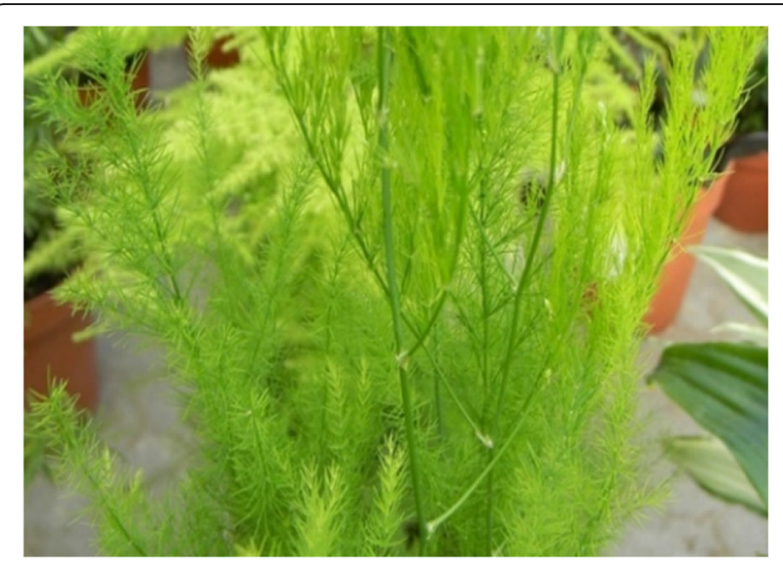

Fig. 1 Image of Asparagus flagellaris

diarrhea and urinary infections [3]. In Unani, the roots are used as laxatives, tonic, aphrodisiac, galactagogue, kidney and liver diseases [4]. Ancient Grecians, Romans, Indians and Chinese used this plant to treat diuretic, cholera and rheumatism [4]. Indians used it to promote fertility, reduce menstrual cramping and increase milk production in nursing mothers. It acts to increase cellular activity in the kidney and thus, increases the rate of urine production. Chinese pharmacists save the Asparagus roots for their families and friends, believing that it will increase compassion and love [4].

The phytochemical screening of the stem bark and leaves of A. flagellaris showed an appreciable amount of flavonoid and a moderate amount of carbohydrate, cardiac glycoside, and saponin reducing sugar, ketones and pentose were detected in trace amount [3]. Mshelia et al. [5] reported the inhibition of six microorganisms viz. Escherichia coli, Corynebacteria, Klebsiella, Neisseria gonorrheae, Shigella dysenteriae and Candida albicans at various concentrations of the ethanol extract of $A$. flagellaris grown in Kokona, Nasarawa state - Nigeria, while the aqueous extract was susceptible to five organisms namely Corynebacteria, Streptococcus pyogenes, Proteus spp., Neisseria gonorrhoeae and Treponema pallidum.

The constituents and biological assay of the leaf essential oil of A. flagellaris have not been reported in the literature to the best of our knowledge. Hence, this study was aimed at isolating, qualitative and quantitative

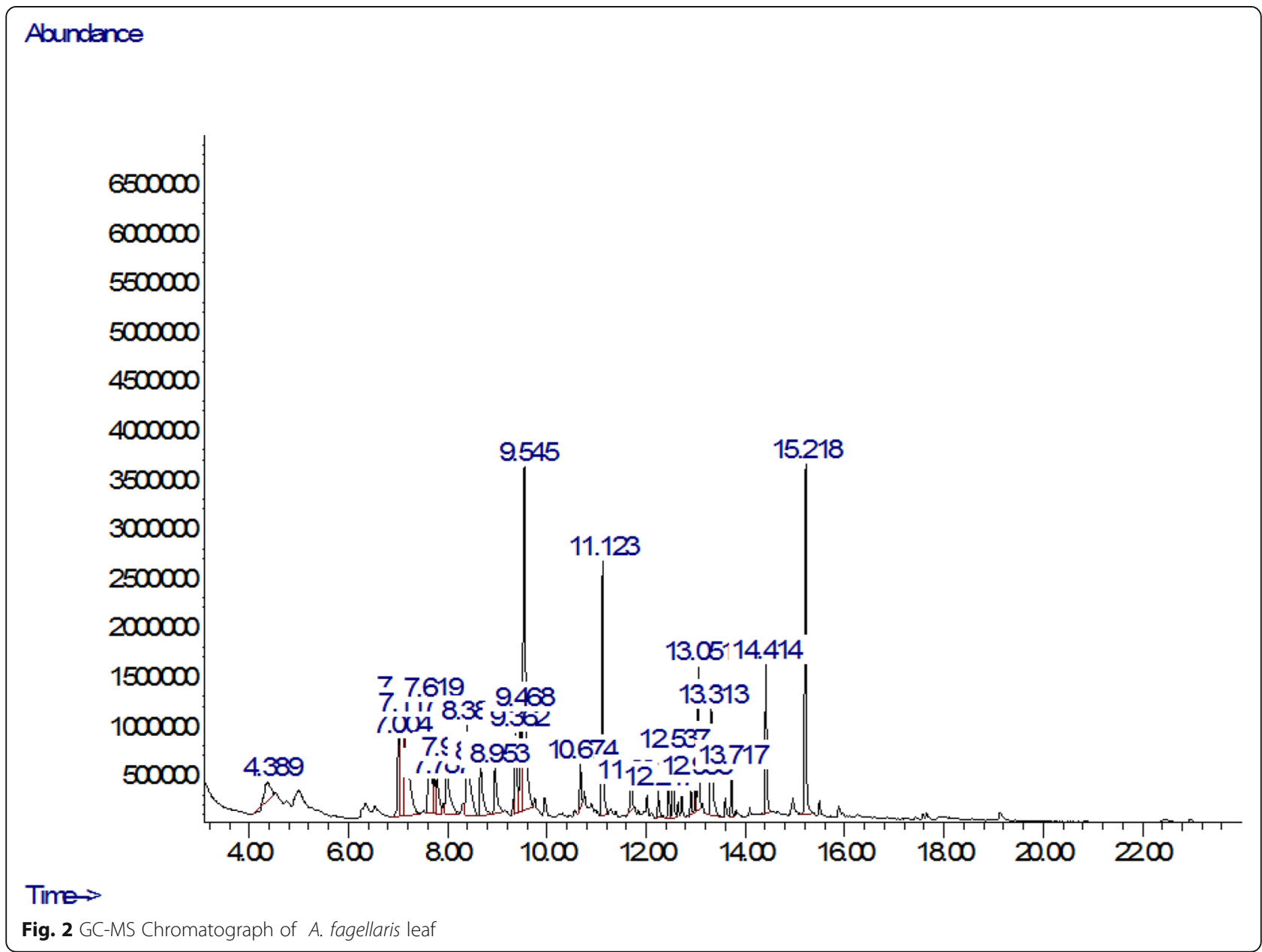


analysis, antioxidant and antimicrobial activities of essential oil from the leaves of $A$. flagellaris.

\section{Material and methods \\ Collection and preparation of the plant materials}

The leaf of A. flagellaris was collected from Efurum town, Delta State, Nigeria in June 2019. It was identified and authenticated at the Herbarium unit of the Botany Department, University of Ibadan, Nigeria. The fresh leaves was air-dried for a week to remove moisture and pulverised. Evaporation of the volatile constituents in the dried plant materials and contamination were avoided by storing the material in air-tight bags before hydrodistillation.

\section{Isolation of essential oils}

Pulverised leaves $(720.10 \mathrm{~g})$ of A. flagellaris was hydrodistilled for $3 \mathrm{~h}$ in an all-glass Clevenger-type apparatus (with a thermo-regulated heating mantle) according to British Pharmacopoeia [6]. The volatile oil distilled over was collected in the receiver arm of the apparatus containing water and analytical grade $n$-hexane (which dissolves the oil). The oil and the hexane were collected into sample bottles. The volatile oils were preserved in a sealed glass vial and stored under refrigeration (at $4{ }^{\circ} \mathrm{C}$ ) before analysis and biological assays. The \% yield of the essential oil was calculated according to the formula below:

$$
\% \text { Yield }=\frac{\text { Weight of essential oil }}{\text { Weight of Sample }} \times 100
$$

Gas Chromatography/Mass Spectrometry (GC-MS).

The essential oil was subjected to GC-MS analysis on an Agilent 7809A Gas Chromatography hyphenated with an Agilent mass detector having split/splitless injector interfaced with mass selective detector operating at 70 $\mathrm{eV}$. The ion source temperature was set to $200^{\circ} \mathrm{C}$ over a mass spectral range of $\mathrm{m} / \mathrm{z} 50-700$ at a scan rate of $1428 \mathrm{amu} / \mathrm{sec}$. The column of the GC used was HP-5MS with a length of $30 \mathrm{~m}$, an internal diameter of $0.25 \mathrm{~mm}$ and a film thickness of $0.25 \mu \mathrm{m}$. The oven temperature was programmed as follows: initial temperature of $80^{\circ} \mathrm{C}$ for $2 \mathrm{~min}$, increased at $10^{\circ} \mathrm{C} / \mathrm{min}$ to a temperature of $240{ }^{\circ} \mathrm{C}$ for 6 mins. Helium was used as the carrier gas at a flow rate of $1 \mathrm{~mL} / \mathrm{min}$. Injection volume, linear velocity and pressure were adjusted at $1.0 \mu \mathrm{L}, 362 \mathrm{~cm} / \mathrm{s}$ and 56.2 $\mathrm{KPa}$, respectively. The oven temperature was set at $60^{\circ} \mathrm{C}$, hold for $1 \mathrm{~min}$ to $180^{\circ} \mathrm{C}$ for $3 \mathrm{~min}$ at $10^{\circ} \mathrm{C} / \mathrm{min}$, the final temperature was $280^{\circ} \mathrm{C}$ for $2 \mathrm{~min}$ at $10^{\circ} \mathrm{C} / \mathrm{min}$ both the injector and detector temperatures were fixed at $250^{\circ} \mathrm{C}$.

Identification of the essential oil components was based on their retention indices as determined with respect to a homologous series of $n$-alkane as well as by comparison of their mass spectral fragmentation patterns (NIST data/base/chemstation data system) with the data previously reported in the literature $[7,8]$. The relative percentages of the essential oil components were obtained by FID peak-area normalisation, all relative response factors being taken as 1 .

\section{Antioxidant assay}

The antioxidant potential of leaves essential oils of $A$. flagellaris was studied using the 2, 2-diphenyl-1-picrylhydrazyl (DPPH) free radical scavenging method described by Brand-William et al. [9] with some modifications. Various concentrations (1000, 500, 250, 125 and $62.5) \mu \mathrm{g} / \mathrm{mL}$ of the essential oil were mixed with $100 \mu \mathrm{M}$ methanolic DPPH solution $(2.0 \mathrm{~mL})$. The mixture was shaken vigorously and left to incubate for $30 \mathrm{~min}$ in the dark at room temperature. The absorbance at $517 \mathrm{~nm}$ was recorded as As and Ab for the sample and blank, respectively using a GS UV-12, UV-Vis spectrophotometer. A blank experiment was carried out applying the same procedure but without essential oils (DPPH + Methanol) and the absorbance was recorded as $A_{C}$. The antioxidant activity of Ascorbic acid and Butylated hydroxyanisole (BHA) were used as standards for comparison. Each experiment was carried out in triplicates and the free radical scavenging activities of the essential oils were calculated as percentage inhibition according to the formula:

$$
\% \text { Inhibition }=\frac{\mathrm{Ab}-\mathrm{As}}{\mathrm{Ab}} \times 100
$$

Where Ab - Absorbance of blank, As - Absorbance of Sample/Reference.

\section{Antimicrobial assay \\ Test organisms}

Ten strains of microbes consisting of six bacteria; four Gram-negative: Escherichia coli, Salmonella typhi, Klebsiella pneumonia and Pseudomonas aeruginosa and two Gram-positive: Staphylococcus aureus and Bacillus subtilis, with four fungi: Candida albicans, Penicillium notatum, Aspergillus niger and Rhizopus spp. were used in this study. All microbes were clinical isolates obtained from the Department of Pharmaceutical Microbiology, University of Ibadan, Oyo State, Nigeria.

\section{Preparation of sample solution [10]}

Oil samples were prepared such that $1 \mathrm{~mL}$ of the oil was regarded as $1000 \mu \mathrm{g} / \mathrm{mL} ; 0.5 \mathrm{~mL}$ of this essential oil was taken into $0.5 \mathrm{~mL}$ of methanol to give $500 \mu \mathrm{g} / \mathrm{mL}$. More serial dilutions gave different concentrations such as $250 \mu \mathrm{g} / \mathrm{mL}, 125 \mu \mathrm{g} / \mathrm{mL}$ and $62.50 \mu \mathrm{g} / \mathrm{mL}$. The 6th, 7(a) 
and 7(b) th test tubes were negative control (DMSO), positive controls; Gentamycin for bacteria and Tioconazole for fungi, respectively.

\section{Antibacterial assay - broth dilution method}

Overnight cultured of microorganisms were prepared by taking two loopful of already grown organisms from the stock and inoculating each into the sterile nutrient broth of $5 \mathrm{~mL}$ each for $18-24 \mathrm{~h}$ at $37^{\circ} \mathrm{C}$. The inoculation of six strains from standardised suspensions was made using a Sterr multi-inoculator using suspensions standardised at 0.5 MacFarland, with a second dilution performed onto BHI inoculum - an approximate concentration of $10^{5}$ $10^{6} \mathrm{CFU} / \mathrm{mL}$ according to the method described by Andrade et al. [11]. From the overnight culture, $0.1 \mathrm{~mL}$ of each organism was added into $9.9 \mathrm{~mL}$ of sterile saline $(0.85 \%)$ to get $10^{-2}$ dilution of each microorganism. From the diluted microorganism, $0.2 \mathrm{~mL}$ was taken into the prepared sterile nutrient agar at $45^{\circ} \mathrm{C}$. This was aseptically poured into the concentrations of each essential oil and controls. The plates were incubated for 18$24 \mathrm{~h}$ at $37^{\circ} \mathrm{C}$. Each experiment was carried in duplicates. The antimicrobial activity was evaluated by measuring the diameter of the inhibition growth zone in millimeters $(\mathrm{mm})$ for the test organisms compared with the control. Gentamicin $(10 \mu \mathrm{g} / \mathrm{mL})$ was used as a positive control.

\section{Antifungal assay via surface plate method}

The sterile Sabouraud Dextrose Agar $(62 \mathrm{~g} / \mathrm{L})$ was prepared accordingly and aseptically poured into the sterile plates and allowed to set; $0.2 \mathrm{~mL}$ of $10^{-2}$ of the fungus was spread on the surface of the set agar using a sterile spreader to cover all the surface of the agar. The wells were made using a cork borer of $8 \mathrm{~mm}$ diameter according to the concentrations and the standard. The essential oil and control were put inside the well as well as the control. The plates were incubated for $48 \mathrm{~h}$ at $28^{\circ} \mathrm{C}$. Tioconazole $(0.7 \mathrm{mg} / \mathrm{mL})$ was used as positive control.

\section{Statistical analysis}

All data represent the means of two or three replicates \pm standard deviation. Results were subjected to analysis of variance (ANOVA) and the mean comparisons were performed by Bonferroni's Multiple Comparison Test using the statistical analysis software package (GraphPadPrism 5). Differences between means were considered significant at $P$-value $<0.05$.

\section{Results}

Hydrodistillation of $720.10 \mathrm{~g}$ air-dried leaves of $A$. flagellaris produced $5.74 \mathrm{~g}$ pale yellow essential oil with a yield of $0.80 \%(\mathrm{w} / \mathrm{w})$ calculated on a dry weight basis. The compositions of the oil is presented in Table 1 and
Figure 2. Twenty-eight (28) compounds were identified from the GC-MS analysis, accounting for $97.41 \%$. The essential oil is composed of a mixture of terpenes, terpenes derivatives and non-terpenes. The DPPH free radical scavenging activity was determined based on \% inhibition of the essential oil to the reference standard. The concentration of the oil and the reference drugs are given in Table 2. Table 3 shows the inhibition zones observed in leaves of $A$. flagellaris essential oil at various concentrations $(1000-62.5 \mu \mathrm{g} / \mathrm{mL})$ compared to the standard drugs to the well diameter.

\section{Discussion}

The leaves essential oil of $A$. flagellaris was dominated with $57.48 \%$ thymol and its derivatives: 5 -thymyl tiglate (18.49\%), thymyl-2-methyl butyrate (17.34\%), thymol hydroquinone dimethyl ether $(10.52 \%)$ and thymol methyl ether $(9.42 \%)$ as shown in Table 1 . However, Willuhn [12] reported five thymol derivatives as the major constituents of the oil of underground organs of $A$. montana, thymol methyl ether inclusive. A similar trend was observed by Weremczuk-Jeżyna et al. [13] where fifty-six compounds were identified in the hairy roots and plant roots of Arnica montana L. oils that consisted mainly of bi-functional thymol derivatives and sesquiterpene hydrocarbons. Hence, thymol and its derivatives are wellknown antioxidants and also inhibited interesting potential against most microorganisms [14].

The leaf essential oil also contains $12.99 \%$ oxygenated sesquiterpenes that are of pharmacological interest, such as 6(3-Isopropenyl-2-methyl-1-cyclopropen-1-yl)-6-methyl-2heptanol, 7-epi-cis-sesquisabinene hydrate, Germacra-4(15), 5,10(14)-trien-1 $\alpha$-ol, Longiverbenone, 8-Cedre-13-ol and cisFarnesol. 15.04\% hydrocarbon sesquiterpenes (Germacrene $\mathrm{D}, \beta$-Copaene, $\Upsilon$-Muurolene, $\beta$-Bisabolene, $\delta$-Cadiene, $\Upsilon$ Cadine-1,4-diene, $\alpha$-Muurolene, Valence, $\alpha$-Patchoulene and 8,9-dihydro-cycloisolongifolene), 6.62\% oxygenated monoterpenes (Bornyl acetate, 5-Propyl-1,3-benzodioxol, 2-Allyl-pcresol and (E)-Cinnamyl alcohol), $0.75 \%$ oxygenated diterpene (phytol) and $4.55 \%$ non-terpenes/non-terpenoids.

However, the constituents of the leaves essential oil of A. flagellaris with interesting biological activities such as thymol methyl ether, bornyl acetate, thymol and $\beta$ bisabolene were also identified as the most abundant constituents in the root essential oil of Chaerophyllum villosum that inhibited significant antioxidant and antimicrobial activities $[15,16]$. Germacrene D, farnesol, bornyl acetate, $\beta$-bisabolene have been reported to be responsible for the antimicrobial and antioxidant of Eupatorium adenoporum essential oil [17]. Dob et al. [18] reported the following constituents; thymol, thymol methyl ether, $\gamma$-Muurolene, Germacrene $\mathrm{D}$ and $\alpha$ Muurolene in Thymus fontanesii are susceptible against all filamentous fungi ( $F$. oxysporum f. sp. albedinis and 
Table 1 Constituents of Essential oil from the leaf of A. flagellaris

\begin{tabular}{|c|c|c|c|}
\hline $\mathrm{S} / \mathrm{N}$ & Identified Compounds & Retention Time & Composition (\%) \\
\hline 1 & Thymol methyl ether ${ }^{f}$ & 5.425 & 9.42 \\
\hline 2 & Bornyl acetate ${ }^{a}$ & 6.192 & 0.44 \\
\hline 3 & Thymol $^{f}$ & 6.387 & 1.71 \\
\hline 4 & Thymol hydroquinone dimethyl ether ${ }^{f}$ & 8.092 & 10.52 \\
\hline 5 & Germacrene $D^{b}$ & 8.849 & 3.83 \\
\hline 6 & $\beta$-Copaeneb & 8.906 & 0.87 \\
\hline 7 & $\beta$-Bisabolene ${ }^{b}$ & 9.439 & 0.92 \\
\hline 8 & $\delta$-Cadinene ${ }^{b}$ & 9.558 & 2.69 \\
\hline 9 & cis-Farnesol ${ }^{\mathrm{C}}$ & 9.592 & 1.51 \\
\hline 10 & $\curlyvee$-Cadine-1,4-dinene ${ }^{b}$ & 9.616 & 0.37 \\
\hline 11 & $a-M u u r o l e n e^{b}$ & 9.635 & 0.83 \\
\hline 12 & Valencene $^{\mathrm{b}}$ & 10.035 & 1.39 \\
\hline 13 & Thymyl-2-methylbutyrate ${ }^{f}$ & 10.035 & 17.34 \\
\hline 14 & a-Patchoulene $e^{b}$ & 10.273 & 2.13 \\
\hline 15 & Thymyl tiglate ${ }^{c}$ & 10.449 & 18.49 \\
\hline 16 & 6-(3-|sopropenyl-2-methyl-1-cyclopropen-1-yl)-6-methyl-2-heptanol $\left.\right|^{c}$ & 10.873 & 3.4 \\
\hline 17 & 7-epi-cis-sesquisabinene hydrate ${ }^{c}$ & 11.063 & 5.46 \\
\hline 18 & $\Upsilon$-Muurolene $\mathrm{b}^{\mathrm{b}}$ & 11.116 & 2.01 \\
\hline 19 & Germacra-4(15),5,10(14)-trien-1a-ol ${ }^{c}$ & 11.225 & 0.31 \\
\hline 20 & 8,9-Dihydro-cycloisolongifolene ${ }^{\mathrm{b}}$ & 11.249 & 0.39 \\
\hline 21 & 2-Ethylbenzimidazole $e^{e}$ & 11.363 & 1.64 \\
\hline 22 & 3-Chloro-4-fluorophenol ${ }^{\mathrm{e}}$ & 11.697 & 2.91 \\
\hline 23 & 5-Propyl-1,3-benzodioxole ${ }^{a}$ & 12.111 & 4.59 \\
\hline 24 & Longiverbenone $^{c}$ & 12.344 & 2 \\
\hline 25 & 2-Allyl-p-cresol $\left.\right|^{a}$ & 13.125 & 0.37 \\
\hline 26 & (E)-Cinnamyl alcohol ${ }^{a}$ & 13.644 & 1.22 \\
\hline 27 & Phytol $^{d}$ & 15.268 & 0.75 \\
\hline \multirow[t]{2}{*}{28} & 8-Cedre-13-ol ${ }^{c}$ & 15.797 & 0.31 \\
\hline & Total & & 97.82 \\
\hline
\end{tabular}

$\mathrm{a}=$ Oxygenated monoterpenes; $\mathrm{b}=$ Sesquiterpenes hydrocarbon; $\mathrm{c}=$ Oxygenated sesquiterpenes; $d=$ Oxygenated diterpene; $\mathrm{e}=$ Non-terpenes, $\mathrm{f}=$ Thymol and derivatives

M. ramanianus), all yeast (S. cerevisiae and C. albicans). Thymol and thymol methyl ether were among the major components identified in the essential oil of Thymus vulgaris that demonstrated antioxidant and antimicrobial activities [19].
However, the biological activities could be associated to the synergistic or antagonistic effect due to complex interactions between the identified chemical components in the essential oil. The ethnomedicinal application of this plant in the treatment of syphilis, gonorrhea and other

Table 2 Antioxidant Activity of the leaves essential oil of A. flagellaris showing \% Inhibition at different concentrations and reference standard

\begin{tabular}{|c|c|c|c|c|c|}
\hline \multirow{2}{*}{$\begin{array}{l}\text { Test } \\
\text { samples }\end{array}$} & \multicolumn{5}{|c|}{$\%$ Inhibition at each Concentration $(\mu \mathrm{g} / \mathrm{mL})$} \\
\hline & 1000.0 & 500.0 & 250.0 & 125.0 & 62.50 \\
\hline APAF & $91.04 \pm 0.0000$ & $90.74 \pm 0.0001$ & $90.59 \pm 0.0000$ & $89.40 \pm 0.0000$ & $88.06 \pm 0.0001$ \\
\hline Ascorbic acid & $93.05 \pm 0.0006$ & $92.87 \pm 0.0006$ & $92.78 \pm 0.0012$ & $90.49 \pm 0.0001$ & $90.40 \pm 0.0000$ \\
\hline BHA & $92.60 \pm 0.0006$ & $91.96 \pm 0.0000$ & $91.41 \pm 0.0000$ & $91.32 \pm 0.0000$ & $90.68 \pm 0.0012$ \\
\hline
\end{tabular}

APAF: Leaf essential oil of $A$. flagellaris, BHA: Butylated hydroxyanisole, $\pm=$ Standard deviation 
Table 3 Antimicrobial Activity of the Leaves Essential Oil of A. flagellaris showing zones of inhibition of the isolates at different concentrations compared to the Standard drugs (with reference to Well diameter of $100 \mathrm{~mm}$ )

\begin{tabular}{|c|c|c|c|c|c|c|c|c|}
\hline \multirow[t]{2}{*}{ Test Organisms } & \multirow{2}{*}{$\begin{array}{l}\text { Negative } \\
\text { Control }\end{array}$} & \multicolumn{2}{|c|}{ Positive Control } & \multicolumn{5}{|c|}{ Inhibitory Zone $(\mathrm{mm})$ at different Concentration $(\mu \mathrm{g} / \mathrm{mL})$} \\
\hline & & Gentamicin & Tioconazole & 1000 & 500 & 250 & 125 & 62.5 \\
\hline Escherichia coli & $(-)$ & 35 & $\mathrm{~N} / \mathrm{A}$ & $(-)$ & $14 \pm 0.00$ & $12 \pm 0.00$ & $12 \pm 0.00$ & $10 \pm 0.00$ \\
\hline Pseudomonas aeruginosa & $(-)$ & 38 & N/A & $(-)$ & $14 \pm 0.00$ & $12 \pm 0.00$ & $(-)$ & $(-)$ \\
\hline Klebsiella pneumonia & $(-)$ & 38 & N/A & $(-)$ & $16 \pm 0.00$ & $13 \pm 0.00$ & $(-)$ & $(-)$ \\
\hline Staphylococcus aureus & $(-)$ & 36 & N/A & $(-)$ & $18 \pm 0.01$ & $15 \pm 0.10$ & $13 \pm 0.10$ & $11 \pm 0.01$ \\
\hline Bacillus subtilis & $(-)$ & 38 & N/A & $(-)$ & $17 \pm 0.00$ & $15 \pm 0.00$ & $13 \pm 0.10$ & $11 \pm 0.01$ \\
\hline Salmonella typhi & $(-)$ & 40 & N/A & $(-)$ & $15 \pm 0.00$ & $12 \pm 0.00$ & $10 \pm 0.00$ & $(-)$ \\
\hline Candida albicans & $(-)$ & N/A & 28 & $(-)$ & $14 \pm 0.00$ & $12 \pm 0.00$ & $10 \pm 0.00$ & $(-)$ \\
\hline Penicillium notatum & $(-)$ & N/A & 28 & $(-)$ & $14 \pm 0.00$ & $12 \pm 0.00$ & $10 \pm 0.00$ & $(-)$ \\
\hline Aspergillus niger & $(-)$ & N/A & 28 & $(-)$ & $12 \pm 0.00$ & $10 \pm 0.00$ & $(-)$ & $(-)$ \\
\hline Rhizopus spp. & $(-)$ & N/A & 28 & $(-)$ & $12 \pm 0.00$ & $10 \pm 0.00$ & $(-)$ & $(-)$ \\
\hline
\end{tabular}

(-): no activity, N/A: not applicable, Mean \pm Standard deviation

sexually transmitted diseases (STDs) [2], diarrhea and urinary infections [3] might, therefore, be attributed to the chemical components present in the leaf A. flagellaris.

In radical form, DPPH absorbs, but upon reduction by antioxidant species, its absorption reduces by hydrogen donating compound, leading to its change in colour, from deep violet/purple to light yellow, which can be monitored spectrophotometrically. It is reported that phenolic compounds are effective antioxidants [20]. Thus, the essential oil in this study contained thymol and its derivatives, oxygenated monoterpenes and oxygenated sesquiterpenes molecules as presented in Table 1 , which are undeniably responsible for the antioxidant activity of this essential oil (see Table 2). The significant antioxidant activity observed in this study using DPPH reduction can be explained by the ability of the identified compounds to donate a hydrogen atom or an electron leading to the formation of $\mathrm{DPPH}-\mathrm{H}$ or to stabilise the free radical, respectively.

It was observed that the \% inhibition of essential oil of A. flagellaris leaves at all tested concentrations possess a significant scavenging power from 91.04\% - 88.06\%, which were competing with the \% inhibition of two of the standards, ascorbic acid (93.09\% - 90.40\%) and BHA $(92.60 \%-90.68 \%)$ used in this study. It was also observed that the antioxidant activities were concentrationdependent. The antioxidant activity observed in this study might be attributed to the chemical components in the essential oil. However, the analysis of variance showed no significant $(P<0.05)$ difference in antioxidant between the essential oil and the reference standards (Ascorbic acid and BHA).

The antimicrobial activity of the A. flagellaris leaves essential oil and reference standards assessed against 10 pathogenic organisms at different concentrations (1000$62.5 \mu \mathrm{g} / \mathrm{mL}$ ). The antimicrobial property was evaluated by measuring the inhibition zones around the well of the essential oil shown in Table 3. The result indicated that the essential oil did not show any inhibition against all tested organisms at $1000 \mu \mathrm{g} / \mathrm{mL}$. No inhibition zone was observed in 125 and $62.5 \mu \mathrm{g} / \mathrm{mL}$ against $K$. pneumonia and $P$. aeruginosa and no inhibition at $62.5 \mu \mathrm{g} / \mathrm{mL}$ against S. typhimurium. No inhibition zones at $62.5 \mu \mathrm{g} /$ $\mathrm{mL}$ against all the tested fungi and $A$. niger and $R$. spp. at $125 \mu \mathrm{g} / \mathrm{mL}$. The leaf essential oil shows moderate inhibition zones at $500-250 \mu \mathrm{g} / \mathrm{mL}$ against all tested organisms for bacteria and fungi. The lowest inhibitory zones were observed in $R$. spp. at $250 \mu \mathrm{g} / \mathrm{mL}(10 \mathrm{~mm})$ but no activity at $125-62.5 \mu \mathrm{g} / \mathrm{mL}$, A. niger at $250 \mu \mathrm{g} / \mathrm{mL}$ but no inhibition at $125-62.5 \mu \mathrm{g} / \mathrm{mL}$ while $C$. albicans and $P$. notatum show the lowest inhibition at $125 \mu \mathrm{g} / \mathrm{mL}$ and no activity at $62.5 \mu \mathrm{g} / \mathrm{mL}$. The difference in antimicrobial activities of A. flagellaris leaves essential oil with respect to reference standards (Gentamicin and Tioconazole) and concentrations were statistically significant $(P<0.05)$.

However, the insensitivity of the oil against tested microorganisms at a higher concentration $(1000 \mu \mathrm{g} / \mathrm{mL})$ might be that only a small amount is needed to attack a specific site in the organism and high concentration will cause accumulation and blockage of the sensitive site, thereby cause no activity [21]. Also, it has been reported that only the non-protein-bound fraction of an antimicrobial is microbiologically active [22], this premise might be attributed to be responsible for the oil in this study to form resistance to the tested microorganisms at the highest concentration assuming it to be proteinbound at higher concentration and this was reduced as the concentration of the oil decreases. The level of antimicrobial activity witnessed in the study might be due to the synergy or antagony of the constituents' presence in the essential oil of the leaves and thus, these chemical 
components can affect multiple target sites against the bacterial cells [23]. This essential oil activity can be described as 'bacteriostatic antibiotic' since it limits the growth by interfering with bacterial protein production, DNA replication, or other aspects of bacterial cellular metabolism. This group of bacteriostatic antibiotic includes tetracyclines, sulfonamides, spectinomycin, etc. [24]. This result correlates with the earlier report by Marchese et al. [25] that described all the thyme essential oils as bacteriostatic against the microorganisms and the one earlier reported on the leaves extracts [5].

\section{Conclusion}

The leaves essential oil chemical composition, antioxidant and antimicrobial activities of A. flagellaris is being reported for the first time. Twenty-eight compounds were identified in the oil sample: mainly oxygenated monoterpenes, hydrocarbon sesquiterpenes, oxygenated sesquiterpenes, and oxygenated diterpene, thymol and its derivatives. The most prominent of the leaf's essential oil are 5-thymyl tiglate, thymyl-2-methyl butyrate, thymol hydroquinone dimethyl ether, thymol methyl ether and 5-propyl-1, 3-benzodioxole. The essential oil exhibited significant antioxidant activity (with \% inhibition of 88.06-91.04) compared with the standard drugs (with \% inhibition of 90.40-93.05) used in this study. The inhibition zones $(10-18 \mathrm{~mm})$ obtained from the antimicrobial assay shows that the essential oil at a concentration between 500 and $125 \mu \mathrm{g} / \mathrm{mL}$ exhibited moderate activity against all the tested microorganisms when compared with the standard drugs (Gentamicin; $10 \mu \mathrm{g} / \mathrm{mL}$ and Tioconazole; $0.7 \mathrm{mg} / \mathrm{mL}$ ) which gave $26-40 \mathrm{~mm}$ inhibition zones. Chemical constituents and the bioactivities of the leaves essential oil of $A$. flagellaris support the ethnomedicinal uses of this plant in treating syphilis, gonorrhea and other sexually transmitted diseases (STDs).

\section{Acknowledgments}

The authors are grateful to Departments of Chemistry and Pharmaceutical Microbiology, Federal University of Petroleum Resources, Effurun, Delta StateNigeria and University of Ibadan, Nigeria, respectively, for providing the laboratory space and facilities for the extraction and analysis of the essential oils.

\section{Authors' contributions}

OOO carried out the sample collection, took part in the laboratory analysis and write up. EOO was involved in the antioxidant and write up. MGI was involved in all the laboratory work, conceptualisation, result interpretation and writing (review and editing). All authors read and approved the final manuscript.

\section{Funding}

Not applicable.

\section{Availability of data and materials} Not applicable.

Ethics approval and consent to participate Not applicable.
Consent for publication

Not applicable.

\section{Competing interests}

Oluwakayode O. Odeja, Michael Gabriel Ibok and Ejike O. Okpala declare that they have no competing interests.

\section{Author details}

'Department of Chemistry, Federal University of Petroleum Resources, Effurun, Delta State, Nigeria. ${ }^{2}$ Department of Chemistry, University of Ibadan, Ibadan, Oyo State, Nigeria. ${ }^{3}$ Department of Chemistry, Federal University Lokoja, Lokoja, Kogi State, Nigeria.

Received: 9 December 2019 Accepted: 29 December 2020 Published online: 22 January 2021

\section{References}

1. Okwu DE, Okwu ME. Chemical composition of Spondia mombin plants. J Sustain Agric Environ. 2004;6:140-7.

2. Vander Burg W. Asparagus fagellaris (Kunth) Baker in PROTA 2. Vegetables/ legumes. Netherlands: Wageningen; 2004.

3. Burkill H. The Useful Plants of West Tropical Africa. London: United Kingdom.; 1985.

4. Krtikar KR, Basu BD. Indian Medicinal Plants. Dehradun.: Bishen Singh Mahendra Pal Singh; 1984.

5. Mshelia EH, Zaria LT, Mohammed AH, Jaji N. Phytochemical Analysis and Antibacterial Screening of Asparagus flagellaris (Kunth) Bak., used in the Traditional Treatment of Sexually Transmitted Diseases and Urinary Infections. EJESM. 2008;1(2):44-8.

6. Drugs - Therapeutic Used and Pharmaceutical Preparations. London: British Pharmacopoeia. 1981:109.

7. Adams R. Identification of essential oil components by gas chromatography/mass spectrometry., Carol Stream, IL. 5th ed. TX UDA. ISBN 978-0-9981557-2-2: Texensis Publishing Gruver; 2017.

8. Olaoluwa O, Moronkola D, Taiwo O, Iganboh P. Volatile oil composition, antioxidant and antimicrobial properties of Boerhavia erecta L. and Euphorbia hirta L. TPR. 2018;2(3):171-8.

9. Brand-Williams W, Cuvelier ME, Berset C. Use of a free-radical method to evaluate antioxidant activity. Food Sci Technol. 1995;28:25-30.

10. Kalemba D, Kunicka A. Antibacterial and antifungal properties of essential oils. Curr Med Chem. 2003;10:813-29.

11. Andrade BFMT, Barbosa LN, Probst ID, Júnior AF. Antimicrobial activity of Essential Oils. J Essent Oil Res. 2014;26(1):34-40. https://doi.org/10.1080/ 10412905.2013.860409.

12. Willuhn G. Investigation on the Constituents of Arnica Species VII. The Composition of the Essential Oil from the Underground Organs and Flower Baskets of Various Arnica Species. Planta Med. 1972;22:1-31.

13. Weremczuk-Jeżyna I, Wysokińska H, Kalemba D. Constituents of the Essential Oil from Hairy Roots and Plant Roots of Arnica montana L. J Essent Oil Res. 2011;23(1):91-9.

14. Palaniappan K, Holley RA. Use of natural antimicrobials to increase antibiotic susceptibility of drug resistant bacteria. Int J Food Microbiol. 2010;140:164-8.

15. Hayta S, Celikezen FC. Evaluation of essential oil composition, antioxidant and antimicrobial properties of Chaerophyllum crinitum Boiss (Apiaceae) from Turkey: A traditional medicinal herb. J Biol Sci. 2016;16:72-6.

16. Joshi RK. Root essential oil composition of Chaerophyllum villosum Wall. ex DC. from Uttarakhand, India. Am J Essent Oils Nat Prod. 2013;1:34-6.

17. Aumeeruddy-Elalfi Z, Gurib-Fakim A, Mahomoodally F. Chemical composition, antimicrobial and antibiotic potentiating activity of essential oils from 10 tropical medicinal plants from Mauritius. J Herb M. 2016. https://doi.org/10.1016/j.hermed.2016.02.002.

18. Dob T, Dahmane D, Benabdelkader T, Chelghoum C. Composition and antimicrobial activity of the essential oil of thymus fontanesii. Pharm Biol. 2006:44(8):607-12. https://doi.org/10.1080/13880200600897106.

19. Khadidja HB, Nadhir G, Mohamed O, Isabelle B, Mohamed Y. Chemical Composition, Antioxidant and Antimicrobial Activities of the Essential Oils of Three Algerian Lamiaceae Species. Curr Nutr Food Sci. 2017;13(2):97-109.

20. Ruberto G, Baratta M. Antioxidant activity of selected essential oil components in two lipid model systems. Food Chem. 2000;69:167-74.

21. Youmans GP, Peterson PY, Soumers HM. The Biological and Clinical Basis of infectious diseases. London: Longman; 1967. p. 721-5. 
22. Beer J, Wagner CC, Zeitlinger M. Protein binding of antimicrobials: methods for quantification and for investigation of its impact on bacterial killing. AAPS J. 2009;11:1-12. https://doi.org/10.1208/s12248-008-9072-1.

23. Oonmetta-aree J, Suzuki T, Gasaluck P, Eumkeb G. Antimicrobial properties and action of galangal (Alpinia galanga Linn.) on Staphylococcus aureus. LWT Food Sci. Technol. 2006;39:1214-20. https:/doi.org/10.1016/.l.wt.2005.06.015.

24. Pankey GA, Sabath LD. Clinical relevance of bacteriostatic versus bactericidal mechanisms of action in the treatment of Gram-positive bacterial infections. Clin. Infect. dis. 2004;38(6):864-70.

25. Marchese A, Orhan IE, Daglia M, Barbieri R, Lorenzo AD, Nabavi SF, Gortzi O, Izadi M, Nabavi SM. Antibacterial and antifungal activities of thymol: a brief review of the literature. Food Chem. 2016. https://doi.org/10.1016/j. foodchem.2016.04.111.

\section{Publisher's Note}

Springer Nature remains neutral with regard to jurisdictional claims in published maps and institutional affiliations.

\section{Submit your manuscript to a SpringerOpen ${ }^{\circ}$ journal and benefit from:}

- Convenient online submission

- Rigorous peer review

- Open access: articles freely available online

- High visibility within the field

- Retaining the copyright to your article

Submit your next manuscript at $\boldsymbol{\nabla}$ springeropen.com 